\title{
A Desire for Love: Considerations on Sexuality and Sexual Education of People With Intellectual Disability in Poland
}

\author{
Remigiusz J. Kijak
}

Published online: 17 December 2010

(C) The Author(s) 2010. This article is published with open access at Springerlink.com

\begin{abstract}
This article is intended to attract public attention to the fact that people with intellectual disability, despite their delayed sexual development, still remain sexual beings, which is connected with many individual and social consequences. The empirical data collected in this work provides knowledge about biological and psychological conditioning of sexual development of individuals with intellectual disability. However, the problem of sexuality for this population should be further analyzed. One should also think about the possibility of supporting the psychological and sexual development of people with more severe intellectual disability.
\end{abstract}

Keywords Sexuality $\cdot$ Intellectual disability $\cdot$ Men $\cdot$ Women $\cdot$ Sex education · Adolescence $\cdot$ Sexual experience $\cdot$ Poland

\section{An Introduction into the Discussion on the Sexuality of People With Intellectual Disability in Poland}

When one analyses the literature on sexuality, one may think that the consequences of a relocation within symbolic culture, that have taken place and are still going on in connection with the processes of emancipation, found its most radical consequences in the ways of perceiving human sexuality. However, these changes have taken place outside the world of disabled people. Without doubts, we may see that the problem of sexuality has been mostly neglected in the group of people with intellectual disability. It is manifested both by the lack of interest in the sexuality of such people as well as a complete lack of a well prepared conception of sexual education for the disabled in the Polish and European pedagogy. Only recently in scientific publications there have appeared first considerations on the sexual and psychological development of people with intellectual disability.

R. J. Kijak (ه)

Podlesie Street 5/33, 30-667 Cracow, Poland

e-mail: remigiuszkijak@wp.pl

R. J. Kijak

Department of Special Pedagogy, Cracow Pedagogical University, Ingrarden Street 4, Cracow, Poland 
It can be treated as a positive sign that after many years of silence in the Polish special pedagogy there has occurred a breakthrough in this conspiracy of silence connected with the sexuality of the disabled. In the circles of scientists, there are no more doubts that people with intellectual disability - irrespective of its degree-also develop their sexual needs. It can be proved by obvious and obeservable symptoms of their sexuality. Moreover, there are no grounds to depreciate the role of love and creating partner relationships in the lives of such people.

In the subject literature, there is not much research devoted to the sexuality of youth with intellectual disability. Dealing with the topic of sexuality of youth with intellectual disability seems to be both very complicated and difficult. The difficulties result, most of all, from the lack of tradition of dealing with the sexuality of the disabled in the Polish special pedagogy, lack of research on sexuality of people with low and high degree of intellectual disability and various attitudes towards sexuality resulting from differences in universal views. It is also important to remember that the problem of the sexuality of people with intellectual disability is surrounded by general disorientation, many myths and a lot of prejudice. In the existing publications on that subject, it is very difficult to find a full description of the applied methodological tools, many clues are left by the researchers without final clarification and very often they describe their research methods and techniques in a rather general way. This may result from the fact that any form of examining such private issues leads to a social dissonance.

\section{Changes in the Period of Adolescence}

The period of adolescent sexual development among people with intellectual disability usually starts later than among people with average pace of development. The average age of having first menstruation for disabled women is at about the age of 14. According to different research, the first wet dream experience among men with intellectual disability occurs when they are 15 . Usually, among teenagers whose intellectual disability results from disturbances in neurological development the adolescence disorders are 20 times more frequent [12]. A premature sexual development is very rarely observed among such people.

The development of sexual features such as pubic hair, development of genitals and breast is not much different when compared to young people with standard intellectual development [3], when determining the pace of biological development of young women with intellectual disability against the whole population, pointed out a considerable delay in the case of people with intellectual disability. People with medium degree of disability are not a homogenous group and the occurrence of the first menstruation and wet dreams may take place even 3 years later than among able-minded people.

According to the research carried out in the eighties by Goldstein [4, pp. 343-349] young women with intellectual disability menstruate on average for 5.5 day, whereas the average length of menstruation period amounted to 28.3 days. The research conducted by McCabe et al. [11] among teenagers with intellectual disability confirms Goldsteina's results. According to this research, 87.9 teenagers with intellectual disability had regular menstruation periods and the average length of blooding lasted for 5.4 days, whereas an average length of the cycle amounted to 28.3 days. All these results are comparable with the population of intellectually fit women.

Voice breaking, being a considerable lowering of the voice pitch, is a very discernible symptom of boys' sexual development. In the group of young men with intellectual 
Table 1 Evaluation of the sex development of the examined people

\begin{tabular}{|c|c|c|c|c|c|}
\hline \multicolumn{2}{|c|}{$\begin{array}{l}\text { Women with } \\
\text { intellectual disability }\end{array}$} & \multicolumn{2}{|c|}{$\begin{array}{l}\text { Men with intellectual } \\
\text { disability }\end{array}$} & \multicolumn{2}{|c|}{$\begin{array}{l}\text { General index of men and women with intellectual } \\
\text { disability }\end{array}$} \\
\hline $\mathrm{n}$ & $\begin{array}{l}\text { Average age } \\
\text { of the first } \\
\text { menstruation }\end{array}$ & $\mathrm{n}$ & $\begin{array}{l}\text { Average age } \\
\text { of the first } \\
\text { wet dreams }\end{array}$ & $\mathrm{n}$ & $\begin{array}{l}\text { The average age of the first sympotoms of } \\
\text { sexual maturity (menstruation and wet dreams) } \\
\text { in the group of men and women with } \\
\text { intellectual disability }\end{array}$ \\
\hline 42 & 13.4 & 92 & 14.5 & 133 & 14.1 \\
\hline
\end{tabular}

Source: Kijak [7]

disability voice breaking occurs in the same way as among intellectually fit men as it is the result of giving off male sex hormones which happens in a correct way in this group of people. The sex hormones also lead to the increase of external sex organs, especially stimulating testicles to produce reproductive cells. The size and external appearance of such organs among men with intellectual disability don't display any difference when compared to able-minded men.

According to the author's empirical tests ${ }^{1}[6,7]$ one can detect differences as regards the first menstruation and first wet dreams among people with intellectual disability as compared to their intellectually fit counterparts. The data gained as a result of empirical analysis are presented in Table 1 . The views expressed in the subject literature on sexual development of people with high degree of intellectual disability coincide with these results. It should be agreed that people with intellectual disability develop biologically in a similar way to their fit peers. However, one must remember that people with medium degree of intellectual disability are not a homogenous group and the occurrence of the first menstruation and wet dreams may take place even 3 years later than in the group of fit people. According to the conducted research, the first wet dreams among men with intellectual disability occur at the age of 14.5 , whereas the first menstruation takes place when such women are 13.4 years old. As a result of the comparative analysis, one should state that the examined youth with intellectual disability reach their sexual maturity on

\footnotetext{
1 The examination concerning sexuality was conducted from January 2007 to March 2008 on the territory of 3 Polish provinces: kujawsko-pomorskie, dolnośląskie, wielkopolskie within the group of 133 people with deeper intellectual disability, aged 17-25. The examination included also a control group of 133 people with average intellectual level. The examined people took part in doctor and/or nurse interview. The current calendar age of the examined person was taken into account as well as the age of the first menstruation among women and first wet dreams among men. According to these data, sex age of the concerned people was established. The avaluation study of the stage of pubescence was carried out in the case of each person, taking into account the criteria of Tannera's simplified scale. The level of sexual development and all data connected with somatic aspect of their sexual maturity were determined by a school nurse according to Patient's Health Cards and in the case of incomplete cards by consultations with the doctor in charge. The scale of development of secondary sex symptoms [features that appear during adolescence period differentiating an adult from a child such as sex ways and copulatory organs. They also include pubic hair (P), armpit hair (A), development of genitals (X), breast increase (Th), facial hair (Y)]. Additionally, the research made use of an interview questionnaire which tested the knowledge of people with intellectual disability on human sexuality, sexual activity as well as the emotions connected with such activity. The interviews with women were conducted by female psychologists and the results were consulted many times by psychologists and psychiatrists. At every stage of the research procedure, highly ethical standards were provided. All conducted interviews were preceded by receiving the consent of the examined, their parents, teachers in charge and headteachers from their schools.

The research was co-financed by the Polish Ministry of Science and Higher Education within the obtained research grant.
} 
Table 2 Evaluation of the sex development of the examined people

\begin{tabular}{|c|c|c|c|c|c|c|c|c|}
\hline \multicolumn{2}{|c|}{ Pre-pubescent period } & \multicolumn{2}{|c|}{ Early pubescence } & \multicolumn{2}{|c|}{ Mid-pubescence } & \multicolumn{2}{|c|}{ Late pubescence } & \multirow[t]{2}{*}{ Total } \\
\hline $\mathrm{n}$ & $\%$ & $\mathrm{n}$ & $\%$ & $\mathrm{n}$ & $\%$ & $\mathrm{n}$ & $\%$ & \\
\hline 1 & 1 & 13 & 10 & 53 & 40 & 66 & 49 & 133 \\
\hline
\end{tabular}

Source: Kijak [7]

average 2 years later than their fit peers. The achieved results should be compared against the results by other authors. Similar results were obtained by Gawlik et al. [3, pp. 270-274] who claim that the first menstruation among women with intellectual disability occurs at the age of 15 , and the first wet dreams among boys at 16 . The research by Teichert $[15$, pp. 41-53] also confirms this regularity. Evan and McKinlay (1988, pp. 59-69) showed that in the group of people with intellectual disability, the first menstruation occurs on average 13 months later than in their fit peers and was at 13.8 years of age; among men the first wet dreams were at the age of 14 . The above data could be compared with the research results conducted by Walter [16].

The results obtained following the application of Tannera's scale are also worth presenting. It was noted that most of the examined people were at the level of mid $(40 \%)$ or late pubescence (49\%). Only $10 \%$ of the examined were in the period of an early pubescence, and with one person the pre-pubescent period was diagnosed. The empirical data are presented in Table 2.

The research results show that the examined women with intellectual disability don't use the services of a gynaecologist. It was also observed that the examined men couldn't check their testicles on their own. Similarly, the examined women didn't test their breast. The schools don't provide such medical examinations and many parents neglect this important problem.

As early as in the eighties of the twentieth century, Kempton with his group of scientists recognized the necessity of cytological and gynaecological examinations as a very important part of the sexual development of people with intellectual disability. All women, including the disabled ones, need professional gynaecological healthcare. As Kempton writes: "within two-first years, after the occurrence of menstruation, the ovulation periods are generally connected with abnormal womb bleeding, however, thyroid disease, anticonvulsion therapy and neuroleptic drugs may also contribute to these symptoms" [5].

\section{The Knowledge of the People With Intellectual Disability About Physical Changes Happening in Their Bodies}

The research [7] confirms that people with intellectual disability notice physical changes within their bodies. However, in most cases they cannot understand these changes. It seems then, that it is extremely important to prepare the youth with intellectual disability to accept the symptoms connected with their sexual development. Unfortunately, both literature data as well as practical experience show that the above group of people lack sexual education and information. The lack of well devised education both on the part of their families and schools make them get their knowledge either from mass media or other undesirable sources. The lack of adequate knowledge, especially concerning the symptoms of sexual development results in big surprise, fear and uncertainty. 
The empirical material collected in this research shows that the examined youth with moderate degree of intellectual disability gain pretty high level of knowledge about the changes happening in their bodies during the adoscence period. Such composition of the analysed feature may explain the fact that the examined youth may observe these changes in their own bodies. Only $1 \%$ of the examined population of people with intellectual disability have problems to describe the changes of their bodies in adolescence period [7].

Results of the research has shown that the knowledge of the examined people, concerning the changes in the adolescence period, is bigger as regards their own sex than the opposite sex. Further research showed that only $37 \%$ of the examined youth with intellectual disability can correctly define the changes of the opposite sex occurring during adolescence period. They found it most difficult to explain the reasons of menstruation and wet dreams. A small percentage of the examined youth knew the meaning of pubic hairing of the opposite sex although as regards their own sex they could explain this change in their own body. The examined group found it also difficult to decide whether the occurrence of frequent involuntary erections was connected with the adolescence period. About $22 \%$ of the examined people, mainly women, didn't know what erection was and if it was characteristic for that period.

According to the conducted research [7] one can state that the examined youth with moderate degree of intellectual disability reaches extremely low level of knowledge about contraception. It was found that only $10 \%$ of them knew what it was and such group of people was able to name at least three contraceptive methods. The most often quoted were condoms and contraceptive pills. Generally, we can assume that the examined youth with intellectual disability don't know many basic ways of contraception. Almost $90 \%$ of them couldn't explain correctly what contraception was, why it is used or its kinds.

The obtained results show very little knowledge of people with moderate intellectual disability about sexually transmitted diseases (STD). I found that only $2 \%$ of the examined youth with moderate intellectual disability could name at least two sexually transmitted diseases and explain their meaning. The examined group named mycotic diseases and syphylis. It is hard to explain why these two diseases were mentioned, taking into account that no precise answer about mycotic diseases was provided by these people.

\section{Psychological and Sexual Development of People With Intelectual Disability on the Basis of Conducted Research}

Psychological and sexual development is a process that consists of many stages. Each of them is characterized by specific "development tasks", each is built upon the previous one and forms a basis for the next stage (see [15] Sexual development is a dynamic process, where biological and social factors interfere with each other. According to Imieliński [1] the biological factors include genetic conditions, morphological and constitutive conditions as well as biochemical and physiological ones. Environmental infuence, in Imieniński's opinion, is represented by physical factors, psychological factors as well as social and cultural ones. As Beisert [2, p. 12] claims, the psychological and sexual development may be treated as acquiring by a human of new sexual experiences, which later will be accumulated in their psyche and may constitute an example how to behave in the future.

In this article two forms of sexual activity of the youth with intellectual disability are going to be presented: masturbation and petting. 
Masturbation as a Main Form of Reducing Sexual Tension

Because of a limited character of the research into sexual functioning of the people with intellectual disability, it is hard to draw some general conclusions. It is a fact that in this group of people, masturbation behaviour does occur, but still not much is known about the degree of this phenomenon among the discussed group of people.

There are many opinions presented in the subject literature and very often they are even contradictory with each other. On the basis of presented research [7], it was found that most of the examined youth with moderate intellectual disability engage in this kind of sexual behaviour. One may state, according to the research, that the frequency of masturbation in the examined group doesn't decrease as their age progresses. This phenomenon reaches its peak at the age of 17-20, however, it occurs equally frequently with older youth. Following the empirical analysis, it was found that as much as $76 \%$ of the examined youth with moderate intellectual disability masturbate. Such young people more often retreated from social sexual behaviour i.e. they more rarely undertook social sexual behaviour aimed at another person such as necking, petting or first sexual contacts. It was found that the age contributes to the development of the process of precise determination of one's sexual desire. It influences the natural course of the process from auto-erotic behaviour to different forms of contacts with a partner.

When exploring the phenomenon of masturbation, we can also trace the places where it occurred. It should be acknowledged that $100 \%$ of the youth with intellectual disability experienced this kind of behaviour alone at home. Exact analysis of the empirical material allowed me to draw further conclusions. It was found that this group of youth experienced masturbation practices also outside home in such places as schools, parks, green squares, public toilets, shops, trams, buses, forests and even infirmaries. According to these findings, we can assume that for $15 \%$ of such young people, masturbation, besides releasing their sex tension, fulfills also other functions such as emotional contact i.e. the need to attract somebody's attention. We may claim that for $15 \%$ of the youth, public masturbation connected with elements of exhibitionism could be a form of attracting somebody's attention and satisfying in this way their need of contact with another person. In most cases, that exhibitionism masturbation involved demonstrating one's sexual organs and proper masturbation in order to satisfy one's sexual needs.

\section{Petting as a Way of Fulfilling Love With a Partner}

A very important part of a young person entering an adult world is to establish close feelings and sexual relationships with others. In comparison to the masturbation described above, petting is a sexual activity involving two people and based on mutual interrelation of both partners, and as a result, it is a higher level of human sexual development. On the basis of the research analysis [7] it was found that 32 people with moderate intellectual disability were involved in sexual caressing with their partners, which accounts for $24 \%$ of the whole sample population.

The research [7] shows that for the majority of the examined people with intellectual disability, petting meant caressing the whole body of their partners, without a sexual intercourse. Most of these people- $85 \%$ started this form of sexual activity out of curiosity, whereas for $35 \%$ of them, the relationship itself also mattered. It was perceived as a need to get closer to another person. The frequency of petting among the examined people depended on having a stable partner. Most of the people who claimed that they have had petting experience said that they had done it only once. However, they said that 
if they could repeat that experience, they would do it again. Only $11 \%$ of the examined admitted regular petting activity with their partner, and in this group all such people had a stable partner. For them, also the atmosphere was important, and in most cases the petting activity took place at home while their parents or other family members were absent.

\section{Love as an Important Aspect of Psychological and Sexual Development of People With Intellectual Disability}

There are not many publications from special pedagogy and psychology of rehabilitation dealing with dating or marriages of people with intellectual disability. Levitz and Kingsley were the first to elaborate on this subject [8]. The researchers emphasize that both interpersonal and social skills are necessary while learning how to date. Such advice should be offered as part of school syllabus from social issues long before first dating takes place. Levitz and Kingsley [8] established that most people with intellectual disability examined by them, knew what a marriage was as they had taken part in some marriage ceremonies before. They are also aware of the need to prepare for a marriage, that young people should get to know each other before they decide to get married and that falling in love is not enough.

The examined people with intellectual disability were willing to talk about love and could describe it by providing some definitions. In many of their answers, one could detect a longing for another person, for being able to hug somebody close to them, going out with somebody or having a date. Their interest in sexual issues was very high, and the need to express these emotions in a way of a physical contact with another person even higher. The statements by this group quoted below can precisely illustrate a very deep need to experience love and feelings in a relationship with a partner:

Tomek, aged 22 (person with deeper intellectual disability)

(...) As I am a man, I can also become a grandfather, uncle, brother. I am already an uncle as my brother has got a child so I am his uncle. Husband is a man and wife is a woman. I can certainly have a family. Family is a mother, a father, a child and home. You can live for somebody. They should love each other. They must kiss and hug each other. I want to have a family. I am finishing my school in a year. I don't feel like going and doing anything. What's the use of walking. It's boring. I'm going to start a family. Ania is going to be my wife. I haven't told her yet that I want her to be my wife. She's going to have a surprise. My dear Ania. I love her, she is my girlfriend. I will have duties when I become a husband-to work and take care of my wife. My wife must clean, wash, cook. I have got her picture. Would you like to see it? She's pretty, isn't she? Have you got a girl-friend as well? Have you got her picture? She's also pretty. Do you love her? I also love mine very much. I don't talk to anybody about that (...).

Example of Ania, aged 23 (person with deeper intellectual disability)

(...) I would even like to hug a boy, Adam, that would be nice. But I won't kiss as I can't have a baby. I don't go for dates because you must have a boyfriend and I don't. Love is something when you love somebody. Love with my mother. I watch films where they kiss (...). 
The above quoted utterings prove that people with intellectual disability develop sexual needs, needs of closeness and being with another person. Each of these two people has certain sexual experiences and each of them expresses the need to have somebody close.

\section{On the Opposite Poles of the Sexual Education of People With Intellectual Disability}

For almost 20 years (since the recognition of the sexuality rights of the people with intelectual disability) no syllabus, even basic one, of the education for such people has been created. The sexuality of the disabled has been completely turned into a taboo, removed, silenced and pushed into background. Very often, the only source of knowledge about sexuality for them are pornographic magazines, the Internet, films that are coarse and imbrued with sex and erotic games. Reading all these pornographic magazines becomes an exemplary lesson on love, partnerships and relation with opposite sex. With such sexual education, it becomes a great surprise for over 20 years old men and women to discover contraceptives, very often described as "funny balloons with no specific use".

The lack of knowledge about sexually transmitted diseases becomes a really important problem. As Kościelska [9] writes "The myth about the asexuality of the handicapped, so common in our society, makes their sexual education seem useless. As a result, we meet adult people with intellectual disablity who haven't received even the basic knowledge connected with their sex". Research dealing with sexual experiences of people with intellectual disability proves their obvious shortage of information on the subject of sexual life. This lack of knowledge often makes them completely helpless as regards human sexuality.

At the end of this part, let's quote the recent SIECUS document (Sexuality Information and Education Council of the United States) which states that "sexuality is a part of a human being worth both serious consideration and respect" as well as confirms the rights of all humans to have correct information, accesible education on sexuality and sexual health service irrespective of their sex, race, ethnic and social origin or disability [13].

\section{The Rights of People With Intellectual Disability}

United Nation Organization, World Health Organization, Declaration of Sexual Rights, European Union and many other world organizations and associations as well as motions passed at various international congresses, meetings and symposiums grant people with intellectual disability the right to experience and develop their sexuality. On the other hand, these rights are obviously violated in various provisions of many legal documents. One should quote here as an example Art. $12 \S 1$ of the Polish Family and Care Code "A person with mental illness or mentally retarded is not allowed to get married. However, if their health or mental condition do not pose a threat to their marriage nor the health of their future offspring and moreover if such person has not been completely incapacitated, the court may allow them to marry".

In 2002 appeared the Declaration of Sexual Rights prepared by World Association for Sexual Health and accepted by World Health Organization. The Declaration states that "Sexuality is an integral part of human personality. Its full development depends on satisfying basic human needs such as having contacts with others, intimacy, expression of feelings, satisfaction, affection and love. Sexual rights are universal human rights basing on inalienable freedom, dignity and equality of all humans. As health is a basic right of 
every human, the same should apply to their sexual health. In order to provide a sound development of sexuality of humans and societies, the following rights must be recognized, promoted, respected and defended by all societies using all their means. Sexual health results from the society that recognizes, respects and applies these sexual rights. Right to sexual equality applies to all forms of discrimination irrespective of sex, sexual orientation, age, race, social class, religion or physical or emotional disability" [10, p. 265]. The rights of the disabled are guaranteed by the Constitution of the Republic of Poland. These rights were also placed in 1993 in Standard Rules of Providing Equal Chances for the Disabled [14], which contains the following statement: “(...) Disabled people cannot be refused the opportunity to experience their own sexuality, have sexual life and parenthood. Having in mind all difficulties that the disabled might encounter in getting married and starting a family, all states should provide easy access to proper advice (...)". In spite of many regulations and numerous world documents devoted to this topic, the rights of the disabled as regards their sexuality are still being violated. There is a lack of system solutions that would take into account the missing link of a "protected marriage" institution.

\section{Ending}

The research into sexuality allows us to formulate the conclusion that men and women with intellectual disability are sexual beings, able to procreate. It should be acknowledged that in the case of disabled women the procreation may constitute some hazard for her and her offspring. The researchers warn also of the possibility of giving birth to a child with different deformations and development anomalies.

The analyses presented in this work were meant to attract public attention to the fact that people with intellectual disability, despite their delayed sexual development, still remain sexual beings, which is connected with many individual and social consequences. The empirical data collected in this work have provided knowledge about biological and psychological conditioning of sexual development of people with intellectual disability. The problem of sexuality of people with intellectual disability should be further analysed. One should also think about the possibility of supporting the psychological and sexual development of people with deeper intellectual disability.

Open Access This article is distributed under the terms of the Creative Commons Attribution Noncommercial License which permits any noncommercial use, distribution, and reproduction in any medium, provided the original author(s) and source are credited.

\section{References}

1. Imieliński, K.: Sexology, vol. 1, 2. Art. 12, § 1 Polish Family and Caring Code, Warszawa (1990)

2. Beisert, M. (red.): Sexuality in the course of human life. Zakład Wydawniczy Z. Domke, Poznań (2004)

3. Gawlik K., Nowak K., Zalewski T.,: The speed of biological maturing of lightly mentally handicapped women against their healthy peers, Special school, 5, (1995)

4. Goldstein, H.: Menarche, menstruation, sexual relations and contraception of adolescent females with down syndrome. Eur. J. Obstet. Gynecol. Reprod. Biol. 27, (1988)

5. Kempton W., Bass, M.S., Gordon, S.: Sexuality and people with intellectual disabilities: a historical perspective. Sex. Disabil. 9, (1985)

6. Kijak, R.: Problems of the sexes, sexuality, maturing-intimate spheres of life of people with intellectual disability. Special school, 5, (2009) 
7. Kijak, R.: Sex and disability—sexual experience of people with intellectual disability. Impuls, Kraków (2009)

8. Kingsley, J., Levitz, M.: Count us. In: Orlando, F.L. (ed.) Growing up with down syndrome. Harcourt Brace, London (1994)

9. Koscielska, M.: Whether and how to support the development of sexual personality identity among people with intellectual disability. (ed.) A. Firkowska-Mankiewicz (ed. in chief.) Emotional and family life of people with intellectual disability in the aspect of their sexuality], (2003)

10. Lew-Starowicz, Z., Długołęcka, A.: Sexual education, Ed. Świat Książki, Warszawa (2006)

11. McCabe, M., Cummins, R.A., Deeks, A.A.: Sexuality and quality of life among people with physical disability. Sex Disabil, 18 (2000)

12. Rowe, W.S., Savage, S.: Sexuality and the developmentally handicapped: a guide look for health care professionals. Mellen, Lewiston (1987)

13. Sexuality and Intellectual Disability Fact Sweet AAMR COMMITTEE

14. Standard rules of providing equal chances for the disabled adopted during 48th UN session on 20 December 1993, (Resolution 48/96) Rule 9, p 2. (1993)

15. Teichert, H.: Psychological and sexual development of people with damaged eye-youth period, part I, Psyche, 4, (1999)

16. Walter, J. (ed.): Sexualitat und geistige Behinderung. Heidelberg (1986) 